\title{
Moxifloxacin and bilateral acute iris transillumination
}

\author{
Robert M Knape*, Fouad E Sayyad and Janet L Davis
}

\begin{abstract}
Recent publications have alerted clinicians to a syndrome of uveitic transilluminating iris depigmentation associated with systemic fluoroquinolones and other antibiotics. Bilateral acute iris transillumination, which is associated with loss of the iris pigment epithelium and results in iris transillumination, differs from the previously described bilateral acute depigmentation of the iris, which is associated with atrophy of the iris stroma without transillumination. We present a case of fluoroquinolone-associated uveitis with anterior segment optical coherence tomography imaging to highlight some observations about this syndrome. We interpret pharmacokinetic data to help explain why oral, but not topical, moxifloxacin may cause fluoroquinolone-associated uveitis.
\end{abstract}

Keywords: Moxifloxacin, Fluoroquinolone, Uveitis, Iris transillumination, Pigment dispersion

Dear editor:

Recent publications have alerted clinicians to a syndrome of transilluminating iris depigmentation associated with the use of systemic fluoroquinolones and other antibiotics $[1,2]$. This syndrome, termed bilateral acute iris transillumination by some authors [1], differs from the previously described bilateral acute depigmentation of the iris, which causes reversible atrophy of the iris stroma without iris transillumination [3]. In contrast, fluoroquinolone-associated uveitis preferentially targets the iris pigment epithelium, leading to irreversible iris transillumination [2].

We present a case of fluoroquinolone-associated uveitis with anterior segment optical coherence tomography (OCT) imaging to highlight some observations about this syndrome. We interpret pharmacokinetic data to help explain why oral, but not topical, moxifloxacin may cause fluoroquinolone-associated uveitis. We also discuss the possible impact of the presence of the native crystalline lens. Finally, we note that the anterior segment OCT findings suggest that both the iris stroma and iris pigment epithelium are affected in fluoroquinolone-associated uveitis.

* Correspondence: robknape@gmail.com

Bascom Palmer Eye Institute, University of Miami Miller School of Medicine, 900 N.W. 17th St, Miami, FL 33136, USA

\section{Report of a case}

A 70-year-old Caucasian man complained of blurry vision and photophobia in both eyes for 2 weeks. His past medical history was notable for lung cancer and an episode of pneumonia treated with oral moxifloxacin 3 days before the ocular symptoms began. His visual acuity was 20/30 OD and 20/40 OS with intraocular pressures (IOP) of $35 \mathrm{mmHg}$ in both eyes. He had mild corneal edema and symmetric $3+$ anterior chamber pigmented cells (Figure 1A,B). Gonioscopy revealed dense pigment obscuring all angle structures (Figure 1C,D). The posterior segments were normal. Serum laboratory evaluation and polymerase chain reaction of the right eye aqueous humor were negative for HSV, VZV, and CMV. He was treated with topical steroids and cycloplegic and IOPlowering medications with little change in vision, IOP, or pupil size. Retroillumination images at presentation and 2 weeks later showed stable iris transillumination defects (Figure 1E,F,G,H), suggesting an acute, self-limited injury. Anterior segment OCT images of the iris demonstrated thinning, concavity, and adherence to the lens (Figure 2A,B). The patient died from respiratory failure after his 2-week follow-up visit.

\section{Comment}

Previous reports have noted fluoroquinolone-associated uveitis only with systemic fluoroquinolones [1,2]. Pharmacokinetic data may explain why topical administration 

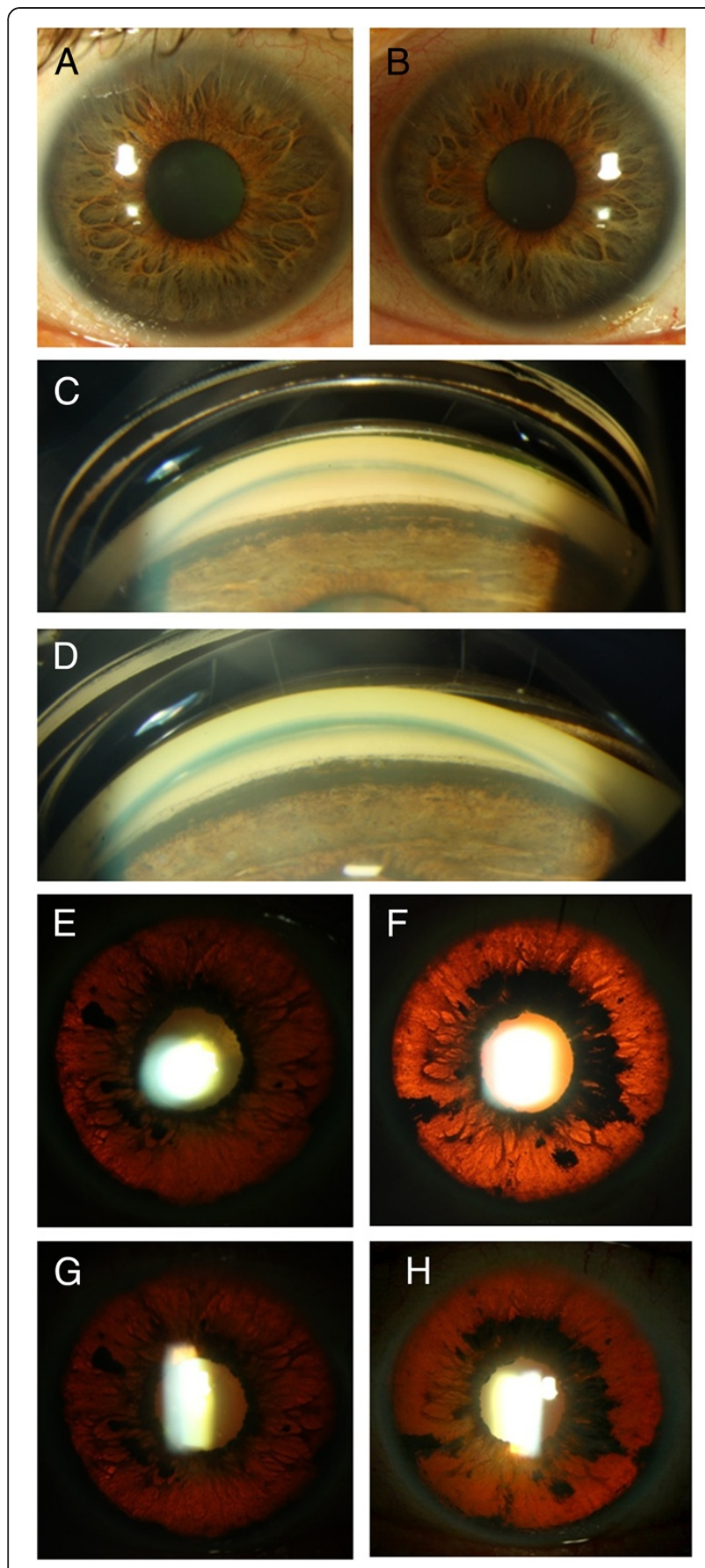

Figure 1 Clinical presentation of the anterior segment. Pigmented cells in the anterior chamber with deposition of a pigmented 'wreath' on the corneal endothelium adjacent to the limbus are seen in the right $(\mathbf{A})$ and left (B) eyes. Gonioscopy shows pigment anterior to Schwalbe's line and extending on to the peripheral iris in the right $(\mathbf{C})$ and left (D) eyes. Transillumination defects noted at presentation in the right $(\mathbf{E})$ and left $(\mathbf{F})$ eyes were stable 2 weeks later in the right $(\mathbf{G})$ and left $(\mathbf{H})$ eyes. has not been associated with this clinical presentation. After topical administration, there is a greater-thantenfold higher concentration of moxifloxacin in aqueous $(2.28 \pm 1.23 \mu \mathrm{g} / \mathrm{mL})$ than in vitreous $(0.11 \pm 0.05 \mu \mathrm{g} / \mathrm{mL})$ [4], whereas oral administration produces similar aqueous $(1.34 \pm 0.66 \mu \mathrm{g} / \mathrm{mL})$ and vitreous concentrations $(1.58 \pm 0.80 \mu \mathrm{g} / \mathrm{mL})$ [5]. The steady serum and vitreous reservoirs of moxifloxacin during oral administration may maintain drug levels in the tissue at risk better than intermittent topical therapy.

The lens status of affected patients may also be relevant. To our knowledge, only phakic patients have been reported with fluoroquinolone-associated uveitis [1,2]. Less drug diffuses posteriorly in phakic eyes [6], and posterior-to-anterior clearance may also be impaired in phakic eyes. Trapping of drug in the posterior chamber by synechiae between an intact lens and the iris, as demonstrated in our OCT (Figure 2), may result in higher drug concentrations adjacent to the posterior layers of the iris.

Why is intravitreal moxifloxacin injection apparently safe [7]? Experience gained from cidofovir-induced uveitis and hypotony indicates that toxicity to the nonpigmented epithelium of the ciliary body is uncommon after intravitreal therapy [8] compared to systemic administration [9], an effect that may be due to the more rapid clearance of intravitreally administered drug compared to recirculation from a serum depot. Additionally, in vitro toxicity studies have not examined the effect on the iris pigment epithelium [10], which may have different susceptibility to moxifloxacin toxicity. Finally, greater light exposure of the iris may have a bearing on the achieved toxicity.

Clinicians confronted with patients with acute onset of uveitis and pigment dispersion should be aware of the association between systemic fluoroquinolones and uveitis. Treatment with corticosteroids for prolonged pigment dispersion after the initial inflammatory phase is likely unnecessary and may contribute to glaucoma in steroid responders. Intraocular pressure would be predicted to improve as the load of pigment in the trabecular meshwork subsides.

Competing interests

The authors declare that they have no competing interests.

\section{Authors' contributions}

RK, FS, and JD confirm that all authors made a direct and substantial contribution to the report by conceiving and designing the study, analyzing and interpreting the findings, writing the manuscript or providing critical revisions, and reading and approving the final version of the manuscript.

\section{Acknowledgements}

The authors wish to acknowledge Brandon M. Sparling, CRA, for the photographic contributions. This study is supported by the NIH Center Core Grant P30EY014801, Research to Prevent Blindness Unrestricted Grant, and the Department of Defense (DOD, grant no. W81XWH-09-1-0675). 

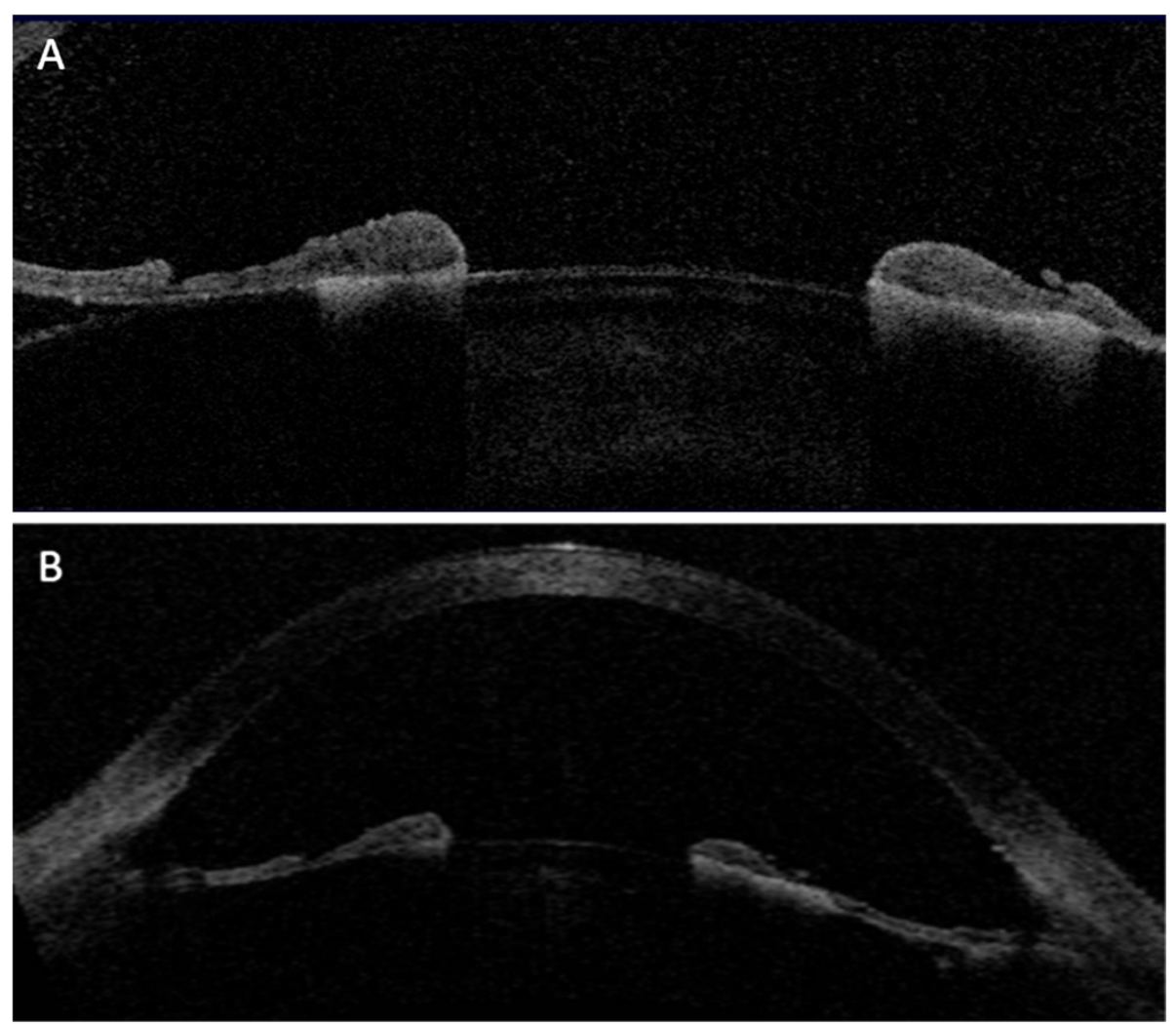

Figure $\mathbf{2}$ OCT of the anterior segment. The right (A) and left (B) eyes show significant stromal thinning with iris concavity and posterior synechiae.

Received: 10 September 2012 Accepted: 12 September 2012 Published: 14 January 2013

\section{References}

1. Tugal-Tutkun I, Onal S, Garip A, Taskapili M, Kazokoglu H, Kadayifcilar S, Kestelyn P (2011) Bilateral acute iris transillumination. Arch Ophthalmol 129 (10):1312-1319

2. Hinkle DM, Dacey MS, Mandelcorn E, Kalyani P, Mauro J, Bates JH, Soukasian SH, Holland GN, Foster CS, Fraunfelder FT, Davis JL, Fraunfelder FW (2012) Bilateral uveitis associated with fluoroquinolone therapy. Cutan Ocul Toxicol 31(2):111-116

3. Tugal-Tutkun I, Araz B, Taskapili M, Akova YA, Yalniz-Akkaya Z, Berker N, Emre S, Gezer A (2009) Bilateral acute depigmentation of the iris: report of 26 new cases and four-year follow-up of two patients. Ophthalmology 116 (8):1552-1557

4. Hariprasad SM, Blinder KJ, Shah GK, Apte RS, Rosenblatt B, Holekamp NM, Thomas MA, Mieler WF, Chi J, Prince RA (2005) Penetration pharmacokinetics of topically administered $0.5 \%$ moxifloxacin ophthalmic solution in human aqueous and vitreous. Arch Ophthalmol 123(1):39-44

5. Hariprasad SM, Shah GK, Mieler WF, Feiner L, Blinder KJ, Holekamp NM, Gao $H$, Prince RA (2006) Vitreous and aqueous penetration of orally administered moxifloxacin in humans. Arch Ophthalmol 124(2):178-182

6. Fuller JJ, McGwin G, Jr (2006) Phakic status affects vitreous penetration of topical moxifloxacin. Arch Ophthalmol 124(5):749. author reply 749

7. Bennett MD, Yee W, Bryan JS (2008) Pegaptanib combined with intravitreal injection of moxifloxacin as treatment of wet macular degeneration. Retina 28(7):976-980

8. Taskintuna I, Rahhal FM, Rao NA, Wiley CA, Mueller AJ, Banker AS, De Clercq E, Arevalo JF, Freeman WR (1997) Adverse events and autopsy findings after intravitreous cidofovir (HPMPC) therapy in patients with acquired immune deficiency syndrome (AIDS). Ophthalmology 104(11):1827-1836. discussion 1836-1837
9. Akler ME, Johnson DW, Burman WJ, Johnson SC (1998) Anterior uveitis and hypotony after intravenous cidofovir for the treatment of cytomegalovirus retinitis. Ophthalmology 105(4):651-657

10. Kernt M, Neubauer AS, Ulbig MW, Kampik A, Welge-Lüssen U (2008) In vitro safety of intravitreal moxifloxacin for endophthalmitis treatment. J Cataract Refract Surg 34(3):480-488

doi:10.1186/1869-5760-3-10

Cite this article as: Knape et al:: Moxifloxacin and bilateral acute iris transillumination. Journal of Opthalmic Inflammation and Infection 2013 3:10.

\section{Submit your manuscript to a SpringerOpen ${ }^{\circ}$ journal and benefit from:}

- Convenient online submission

- Rigorous peer review

- Immediate publication on acceptance

- Open access: articles freely available online

- High visibility within the field

- Retaining the copyright to your article

Submit your next manuscript at $>$ springeropen.com 